\title{
One-step chromatographic procedure for purification of B-phycoerythrin from Porphyridium cruentum
}

\author{
Zhihong Tang ${ }^{\mathrm{a}, *}$, Jilu zhao ${ }^{\mathrm{a}}$, Bao Ju ${ }^{\mathrm{a}}$, Wenjun $\mathrm{Li}^{\mathrm{b}}$, Shaohong Wen ${ }^{\mathrm{a}}$, Yang Pu ${ }^{\mathrm{c}}$, Song Qin ${ }^{\mathrm{b}}$ \\ ${ }^{a}$ College of Life Science, Yantai University, 30 Qingquan Street, Yantai 264005, China \\ ${ }^{\mathrm{b}}$ Yantai Institute of Coastal Zone Research, Chinese Academy of Sciences, 17 Chunhui Street, Yantai 264003, China \\ ${ }^{c}$ College of Agriculture, Ludong University, 186 Hongqizhong Street, Yantai 264025, China
}

\section{A R T I C L E I N F O}

\section{Article history:}

Received 22 January 2016

Received in revised form

26 January 2016

Accepted 29 January 2016

Available online 3 February 2016

\section{Keywords:}

Porphyridium cruentum

B-phycoerythrin

Purification

Chromatography

\begin{abstract}
A B S T R A C T
B-phycoerythrin (B-PE) was separated and purified from microalga Porphyridium cruentum using onestep chromatographic method. Phycobiliproteins in P. cruentum was extracted by osmotic shock and initially purified by ultrafiltration. Further purification was carried out with a SOURCE $15 \mathrm{Q}$ exchange column and analytical grade B-PE was obtained with a purity ratio $\left(A_{545} / A_{280}\right)$ of 5.1 and a yield of $68.5 \%$. It showed a double absorption peaks at $545 \mathrm{~nm}$ and $565 \mathrm{~nm}$ and a shoulder peak at $498 \mathrm{~nm}$, and displayed a fluorescence emission maximum at $580 \mathrm{~nm}$. The analysis by sodium dodecyl sulfate -polyacrylamide gel electrophoresis (SDS-PAGE) showed a bulky band between 18 and $20 \mathrm{kDa}$ which could be assigned to subunits $\alpha$ and $\beta$ and a low intensity band of $27 \mathrm{kDa}$ assigned to $\gamma$ subunit. Our protocol provides attractive alternative to consider for the purification procedure to obtain analytical grade B-PE at commercial level.
\end{abstract}

() 2016 Elsevier Inc. All rights reserved.

\section{Introduction}

Phycobiliproteins (PBPs) are a class of chromoproteins found in red algae, cyanobacteria, cryptophytes, and glaucocystophytes [1-5]. According to their spectral properties, PBPs are commonly classified phycoerythrins (PE, $\lambda_{\max }=540-570 \mathrm{~nm}$ ), phycoerythrocyanins (PEC, $\left.\lambda_{\max }=560-600 \mathrm{~nm}\right)$, phycocyanins $\left(P C, \lambda_{\max }=610-620 \mathrm{~nm}\right)$, and allophycocyanins (APC, $\lambda_{\max }=650-655 \mathrm{~nm}$ ) [6,7]. These proteins are an ensemble of photosynthetic complex called phycobilisome and work as accessory pigments to allow light absorption in the cell on the thylakoids of chloroplast [8-10].

Depending on their absorption spectrum, PE can be divided into three main classes R-PE, B-PE, and C-PE [11]. It has been reported that PE is useful for development of fluorescent probes because of its high extinction coefficients, fluorescence quantum efficiency of more than 0.8 , and stability as hexamers even at lower concentrations without showing fluorescence decrease [12-15]. Moreover, PE can be used as natural colorants in the food, cosmetic industry and as photo sensitizers in tumor photodynamic therapy [16-23]. In case of PE, commercial scale processing of this material continues to be a daunting task. R-PE is usually extracted and

\footnotetext{
* Corresponding author

E-mail address: zhhtang6@163.com (Z. Tang).
}

purified from Porphyra, Grateloupia and Polysiphonia, but most of them contained huge amount of polysaccharides which form gel (carbohydrate) and thereby making the purification task most difficult and tedious [2,24-27]. B-PE is the main phycobiliprotein of Porphyridium species and it contains three subunits $(\alpha \beta)_{6} \gamma$ with molecular weights of $19.5 \mathrm{kDa}$ ( $\alpha$ and $\beta$ subunits) and $29 \mathrm{kDa}(\gamma$ subunit) for a total molecular weight of $263 \mathrm{kDa}$ [10]. This phycoerythrin normally has a double absorption peaks at $\sim 545$ and $\sim 565 \mathrm{~nm}$, and a shoulder peak at $\sim 498 \mathrm{~nm}$, and a fluorescence emission maximum at $580 \mathrm{~nm}$ [11]. The price of B-PE products varies widely and is dependent on the purity ratio $\left(A_{\max } / A_{280}\right)$. The cost of analytical grade B-PE (purity ratio higher than 4.0) can be as high as about 50 US\$/mg [22]. This high value makes attractive attempt to develop an efficient purification procedure to obtain BPE with high purity and yield at commercial level. Previous attempt for analytical grade of B-PE has been reported [9,11,28-30]. However most cases are complicated by the need for multiple chromatography steps to obtain highly purified protein. The complexity of the procedures for purification of B-PE is usually characterized for having a high number of stages, low yield and limitation to easy process scale-up, which limits its potential practical implementation at commercial level [22]. Therefore, it is needed to develop an efficient purification procedure to obtain analytical grade of B-PE with high yield at large scale. SOURCE $15 \mathrm{Q}$ is an ion exchanger of 
high performance separation medium for fast, preparative purification of biomolecules. It is ideal for intermediate purification steps in industrial processes where high productivity and maintained performance at large scale are important. In the present study, we have improved the efficiency of purification step of the routine methods to obtain B-PE from P. cruentum, involving only a one-step chromatography on a SOURCE $15 \mathrm{Q}$ ion exchanger column.

\section{Materials and methods}

\subsection{Biological material}

The microalga P. cruentum were obtained from Laboratory of microalga biotechnology, Yantai University, China. The alga was intensively cultivated in Hemerick culture medium as described before [9,31]. The culture medium and the biomass were separated by centrifuging (CT18RT, Techcomp Instrument Ltd., Shanghai, China) the cell suspension at $10,000 \times \mathrm{g}$ for $10 \mathrm{~min}$. The pellets containing biomass were lyophilized for getting dry biomass.

\subsection{Preparation of crude extracts}

The extraction was carried out using the method of Bermejo et al. [28] with some modification. Freeze-dried samples ( $5 \mathrm{~g}$ ) were resuspended in $50 \mathrm{ml}$ acetic acid-sodium acetate buffer ( $\mathrm{pH} 6.0$, $1 \mathrm{M}$ ). The slurry was mixed with a variable-speed stirrer at $300 \mathrm{rpm}$ for $1 \mathrm{~h}$ and then the slurry was centrifuged at $10,000 \times \mathrm{g}$ for $5 \mathrm{~min}$. The phycoerythrin-rich supernatants were pooled and treated as the crude extract used in the following purification steps (Fig. 1). The following purification procedure included ultrafiltration and chromatography with a SOURCE $15 \mathrm{Q}$ anion exchange column.

\subsection{Fractionation of water-soluble compounds by ultrafiltration}

The crude extract was filtered through PES hollow fiber membrane (GM2540F1073, GE Water \&Process Technologies, Shanghai) with a molecular weight cut off (MWCO) of $30 \mathrm{kDa}, 50 \mathrm{kDa}$ and $100 \mathrm{kDa}$ (shear force $0.1 \mathrm{MPa}$, flow rate $300 \mathrm{~cm}^{3} / \mathrm{min}$, inner diam. $0.8 \mathrm{~mm}$, outer diam. $1.2 \mathrm{~mm}, 4{ }^{\circ} \mathrm{C}$ ). Deionized water was added constantly until the permeate liquid showed no absorption at $260 \mathrm{~nm}$ and $280 \mathrm{~nm}$. The retentate was concentrated and lyophilized to yield $0.20 \mathrm{~g}$ of fluffy red solid which was stored $4{ }^{\circ} \mathrm{C}$.

\subsection{SOURCE $15 Q$ chromatography}

After dissolving $0.20 \mathrm{~g}$ lyophilized retentate in $10 \mathrm{ml}$ sodium phosphate buffer ( $\mathrm{pH} 7.2,20 \mathrm{mM}$ ), the solution was futher purified with a SOURCE 15Q (GE, USA) anion exchange column $(50 \times 16 \mathrm{~mm})$ on a fast protein liquid chromatography (FPLC, AKTA purifier 10, GE, USA). After washing with the same buffer, the column was eluted with a linearly increasing ionic concentration gradient of $\mathrm{NaCl}$ (from 0 to $0.5 \mathrm{M}$ ) at a flow rate of $2.0 \mathrm{ml} / \mathrm{min}$. The eluate with red color was pooled and analyzed.

\subsection{Comparison of the purification efficiency of different chromatography methods}

To compare purification efficiency with SOURCE $15 \mathrm{Q}$ the retentate was also purified on Sephadex G-150 (GE, USA) and DEAE cellulose DE52 (GE, USA) column. $0.15 \mathrm{~g}$ lyophilized retentate was dissolved in $15 \mathrm{ml}$ sodium phosphate buffer and then divided into three equal portions: sample1, sample2 and sample3. For Sephadex G-150 chromatography, sample1 was passed through Sephadex G150 media packed in $(600 \times 25 \mathrm{~mm})$ column equilibrated with $20 \mathrm{mM}$ phosphate buffer $\mathrm{pH}$ 7.2. For DEAE cellulose DE52

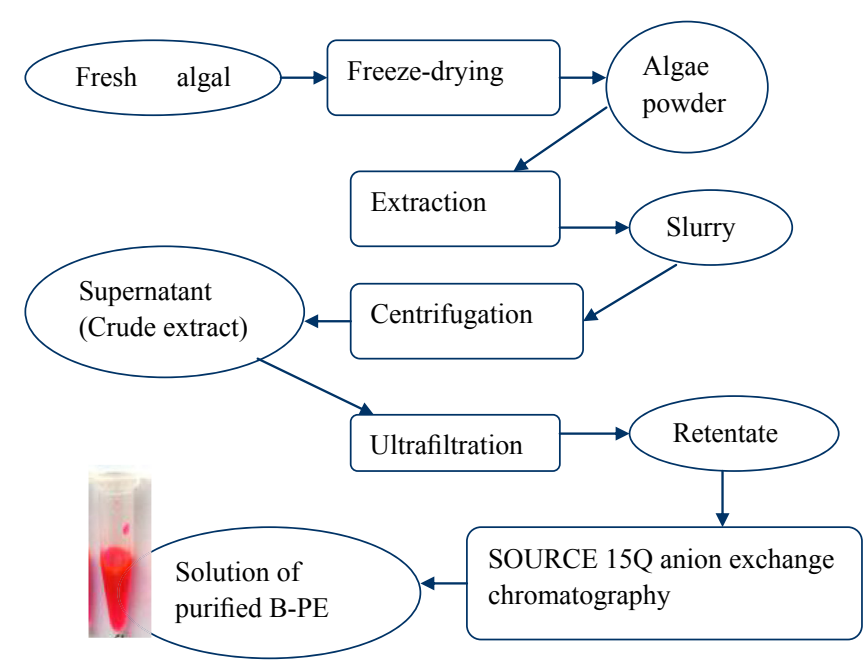

Fig. 1. Schematic diagram for purification of the B-PE from P. cruentum.

chromatography, sample2 was applied to a column $(100 \times 25 \mathrm{~mm})$ of DEAE cellulose DE52, pre-equilibrated with sodium phosphate buffer ( $\mathrm{pH} 7.2,20 \mathrm{mM}$ ). After washing with sodium phosphate buffer ( $\mathrm{pH} 7.2,20 \mathrm{mM}$ ), the column was eluted with a linearly increasing ionic concentration gradient of $\mathrm{NaCl}$ (from 0 to $1 \mathrm{M}$ ) at a flow rate of $1.0 \mathrm{ml} / \mathrm{min}$. Sample3 was applied to a column $(50 \times 16 \mathrm{~mm})$ of SOURCE $15 \mathrm{Q}$ and the procedure was performed as above.

\subsection{Analyses}

Protein content was estimated by Lowry's method using bovine serum albumin (BSA) as protein standard [32]. The absorption spectra of purified B-PE were recorded using a UV-VIS spectrophotometer (UV-1700, Shimadzu, Japan) with a $1 \mathrm{~cm}$ light path. The purity index of BPE was evaluated spectrophotometrically by the absorbance ratio of $A_{545} / A_{280}$. The amounts of B-PE in each step of the process were determined with a previously reported equation system by measures of absorbances at 545,620 and $650 \mathrm{~nm}$ according to Marcati et al. [10]. The fluorescence spectrum of purified B-PE was recorded using a fluorescence spectrometer (F-4500, Hitachi, Japan).

The homogeneity and structure integrity were analyzed by native polyacrylamide gel electrophoresis (PAGE) using a vertical electrophoresis cell (Mini-Protean II, Bio-Rad, USA) with a separating gel of $10 \%$ and a stacking gel of $5 \%$ as described before [33]. After electrophoresis, the protein band corresponding to B-PE was identified firstly by the pink color. Then, protein bands were staining with $0.2 \%(\mathrm{w} / \mathrm{v})$ Coomassie brilliant blue R250.

The molecular weights of the subunits was analyzed by performing sodium dodecyl sulfate-polyacrylamide gel electrophoresis (SDS-PAGE) in a Bio-Rad Miniprotean II vertical slab gel apparatus using Laemmli-buffer system according to $\mathrm{H}$. Schägger and von Jagow [34]. Electrophoresis was carried out using a $12 \%$ polyacrylamide slab gel with $0.1 \%(\mathrm{w} / \mathrm{v})$ SDS and $5 \%$ polyacrylamide stacking gel. Protein bands were detected by staining with $0.2 \%(\mathrm{w} /$ v) Coomassie brilliant blue R250. The molecular weights of the subunits were assayed by calibration with protein molecular weight marker (Broad Range, TaKaRa).

Results presented here are the average of three independent experiments and the mean \pm standard deviation (SD) was less than $\pm 5 \%$. 


\section{Results and discussion}

\subsection{Extraction of $B-P E$}

P. cruentum is a sea water microalga well known for its capacity to produce B-PE in large quantities. In the present study, typical growth conditions for P. cruentum were employed. After 25 days of culture, the biomass achieved was $8 \mathrm{~g}$ of wet biomass per $\mathrm{L}$ and the result is similar to that reported by Ruiz-Ruiz et al. [9]. After harvesting the cell mass, osmotic shock was used to extract the initial protein. The disruption technique can be easily scaled up and is much simple and efficient as compared with the methods that use ultrasound, freeze-thawing or the addition of chemical compounds like TritonX-100, lysozyme and rivanol [28]. In the experiment, the crude extract was obtained and analyzed by a UV-VIS spectrophotometer, the purity ratio $\left(A_{545} / A_{280}\right)$ was 0.9 . The apparent absorption spectrum of crude extract at $545-565 \mathrm{~nm}$ which was the absorption peak for B-PE, indicated a high content of B-PE in $P$. cruentum. Absorbance at 260 and $280 \mathrm{~nm}$ corresponded to a mixture of nucleic acid and protein (Fig. 2).

\subsection{Fractionation of water-soluble compounds by ultrafiltration}

Three membranes, with MWCO of $30 \mathrm{kDa}, 50 \mathrm{kDa}$ and $100 \mathrm{kDa}$, were initially screened for their effect on the retention of B-PE in crude extract. The results revealed the retention rate of B-PE were 98.9\%, 98.1\% and 90.5\% for the $30 \mathrm{kDa}, 50 \mathrm{kDa}$ and $100 \mathrm{kDa}$ cut-off membranes, respectively. The purity ratios of the B-PE retentate obtained by ultrafiltration, when using membranes with MWCO $30 \mathrm{kDa}, 50 \mathrm{kDa}$ and $100 \mathrm{kDa}$ were $1.3,1.7$ and 1.6, respectively. Consider that the retention rate after ultrafiltration with a MWCO $50 \mathrm{kDa}$ membrane was almost not reduced and the purity ratio were higher than those with a MWCO $30 \mathrm{kDa}$ and $100 \mathrm{kDa}$, membrane with MWCO, $50 \mathrm{kDa}$ is suitable for the ultrafiltration process. Ultrafiltration, which is currently gaining importance in the processing of biomolecules/liquids, can be applied to largescale production and is simple to carry out. Moreover, this technique is a very efficient separation technology without addition of chemicals and is normally carried out at ambient temperature, which minimizes thermal damage to the product [35]. Marcati et al. reported that a first ultrafiltration using a membrane with a MWCO

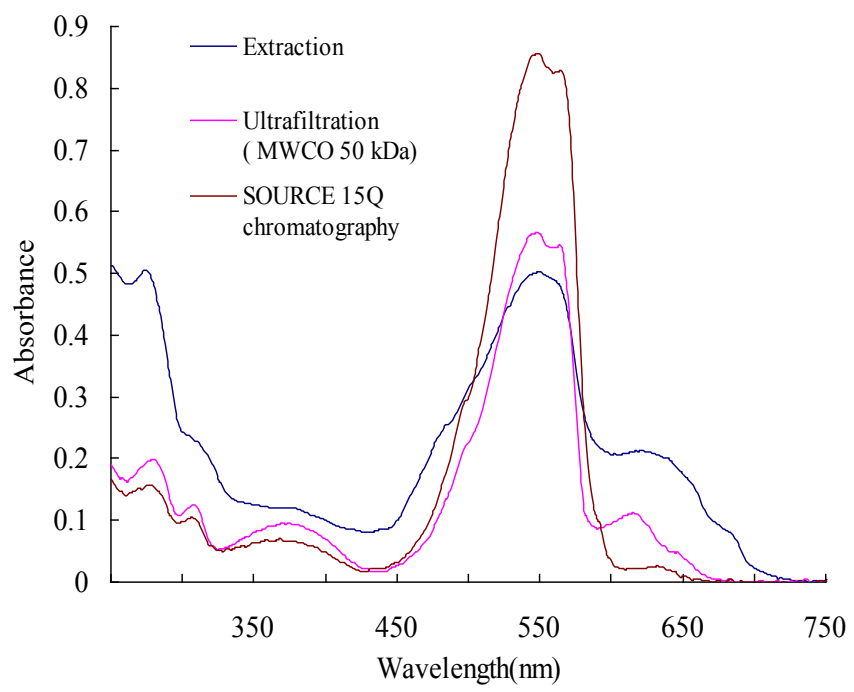

Fig. 2. Absorption spectrum of B-PE from P. cruentum at each step of purification.
Table 1

Purification of B-PE from P. cruentum.

\begin{tabular}{|c|c|c|c|}
\hline Purification step & $\begin{array}{l}\text { Crude } \\
\text { extract }\end{array}$ & $\begin{array}{l}\text { Ultrafiltration } \\
\text { (MWCO } 50 \mathrm{kDa} \text { ) }\end{array}$ & $\begin{array}{l}\text { SOURCE } 15 Q \\
\text { chromatography }\end{array}$ \\
\hline $\begin{array}{l}\text { Total protein } \\
\text { content }(\mathrm{mg})^{\mathrm{a}}\end{array}$ & $305.0 \pm 12.8$ & $168.1 \pm 7.4$ & $59.5 \pm 2.6$ \\
\hline B-PE content $(\mathrm{mg})^{\mathrm{b}}$ & $83.2 \pm 3.2$ & $81.6 \pm 2.9$ & $57.0 \pm 2.1$ \\
\hline $\begin{array}{l}\text { B-PE from total } \\
\text { proteins }(\% \mathrm{w} / \mathrm{w})\end{array}$ & $27.3 \pm 0.9$ & $48.5 \pm 1.3$ & $95.8 \pm 3.4$ \\
\hline B-PE recovery $(\% \mathrm{w} / \mathrm{w})^{\mathrm{c}}$ & 100 & $98.1 \pm 5.2$ & $68.5 \pm 3.7$ \\
\hline $\begin{array}{l}\text { Purity ratio } \\
\qquad\left(A_{545} / A_{280}\right)\end{array}$ & $0.9 \pm 0.1$ & $1.7 \pm 0.1$ & $5.1 \pm 0.4$ \\
\hline
\end{tabular}

Data are expressed as the mean \pm SD $(n=3)$.

a Total protein was determined by Lowry's method.

b B-PE content was determined with equation system by measures of absorbances at 545,620 and $650 \mathrm{~nm}$.

${ }^{\mathrm{C}} \mathrm{B}-\mathrm{PE}$ recovery is expressed relative to the original amount of $\mathrm{B}-\mathrm{PE}$ in the crude extract.

$300 \mathrm{kDa}$ yielded high molecular weight polysaccharides and the resulting $300 \mathrm{kDa}$ permeate was then run through a second MWCO $10 \mathrm{kDa}$ membrane to recover B-PE with a purity ratio of 2.3 [10]. Ruiz-Ruiz et al. reported that ultrafiltration with a MWCO $300 \mathrm{kDa}$ membrane could successfully remove most of polyethyleneglycol (PEG) of B-PE solution [9]. In our study, the B-PE fraction was obtained with a purity ratio of 1.7 and a retention rate of $98.1 \%$ when crude extract ultrafiltration with a MWCO $50 \mathrm{kDa}$ membrane (Table 1). Fraction by ultrafiltration could increase the purity ratio of B-PE approximately 2 fold, compared with the initial purity ratio of the crude extract.

\subsection{SOURCE $15 Q$ chromatography and characterization of B-PE}

The B-PE fraction was further purified with a SOURCE 15Q anion exchange column on FPLC. The column was eluted with a linear gradient of $\mathrm{NaCl}$ in the same buffer at a flow rate of $2 \mathrm{ml} / \mathrm{min}$, resulted in high purity $\left(A_{545} / A_{280}=5.1\right) \mathrm{B}-\mathrm{PE}$ with a yield of $68.5 \%$ (Table 1$)$. The absorption spectra of the purified B-PE had a double absorption peaks at 545 and $565 \mathrm{~nm}$, and a shoulder peak at $498 \mathrm{~nm}$. No absorbance peak was found at 620 and $652 \mathrm{~nm}$ indicated the absence of phycourobilin, C-PC or APC in the purified B-PE sample, while low absorption in the region of $280 \mathrm{~nm}$ suggested

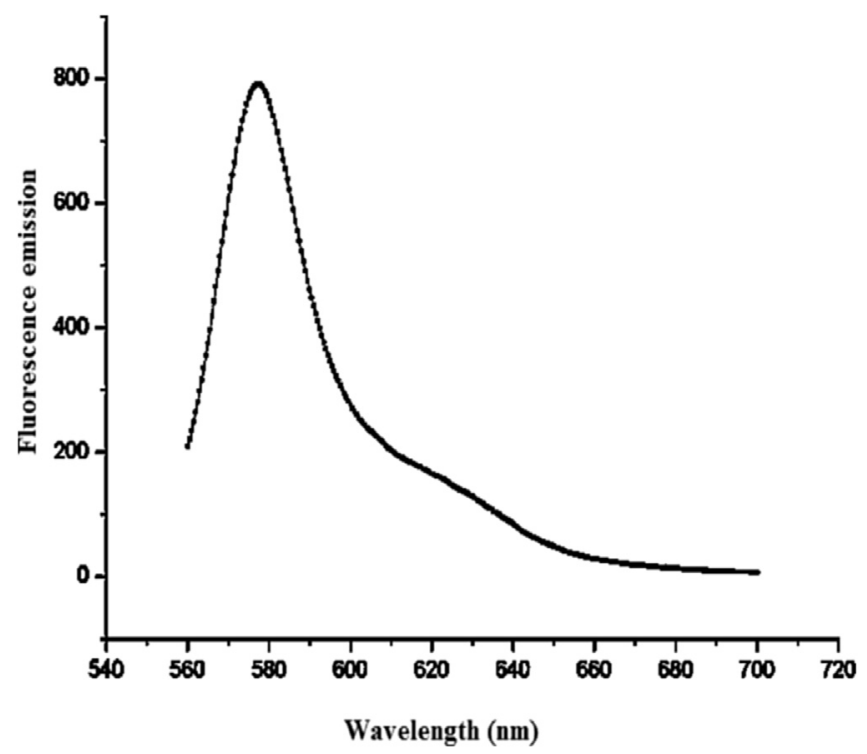

Fig. 3. Fluorescence emission spectrum of purified B-PE from P. cruentum. 


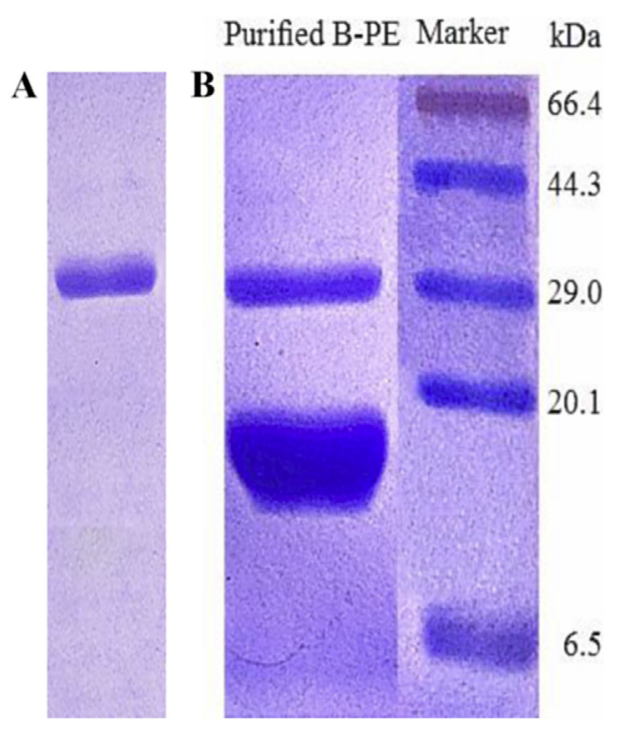

Fig. 4. (A) Native polyacrylamide gel electrophoresis (PAGE) analysis of the purified BPE from P. cruentum. (B) SDS-PAGE analysis of the purified B-PE from P. cruentum.

high purity of the PE in the eluate (Fig. 2). Fluorescence emission spectrum of purified B-PE from $P$. cruentum showed maximum fluorescence at $580 \mathrm{~nm}$ (Fig. 3). These spectra agree well with those published references for pure B-PE [9,11,12,30,36,37]. The homogeneity and structure integrity of the B-PE obtained from the SOURCE $15 \mathrm{Q}$ column were confirmed by the native PAGE which showed only one band (Fig. 4A). The analysis by SDS-PAGE revealed a broad band between 18 and $20 \mathrm{kDa}$ which could be assigned to subunits $\alpha$ and $\beta$ and a low intensity band of $31 \mathrm{kDa}$ assigned to $\gamma$ subunit (Fig. 4B), which consistents with the value reported previously $[9,28,38,39]$.

\subsection{Comparison of the purification efficiency of different chromatography methods}

To compare purification efficiency of SOURCE $15 \mathrm{Q}$, the sample was also purified on media of Sephadex G-150 and DEAE cellulose DE52. Purification efficiency of different chromatography methods is summarized in Table 2. The media of Sephadex G-150 and DEAE cellulose DE52 were screened from several of frequently-used media in previous studies, with relative good purification efficiency. As seen from the table, the B-PE recovery and purity ratio are highest on SOURCE 15Q. The result suggested that purification efficiency of SOURCE 15Q was higher than the other two kinds of

Table 2

Purification efficiency of different chromatography methods.

\begin{tabular}{lcll}
\hline Media & SOURCE 15Q & $\begin{array}{l}\text { Sephadex } \\
\text { G-150 }\end{array}$ & DEAE-cellulose 52 \\
\hline $\begin{array}{c}\text { Protein recovery } \\
(\% \mathrm{w} / \mathrm{w})^{\mathrm{a}}\end{array}$ & $35.2 \pm 1.8$ & $31.6 \pm 1.5$ & $27.9 \pm 1.1$ \\
$\begin{array}{c}\text { B-PE recovery } \\
(\% \mathrm{w} / \mathrm{w})^{\mathrm{b}}\end{array}$ & $68.5 \pm 3.7$ & $58.3 \pm 2.7$ & $52.6 \pm 2.6$ \\
$\begin{array}{c}\text { Purity ratio } \\
\left(A_{545} / A_{280}\right)\end{array}$ & $5.1 \pm 0.4$ & $3.8 \pm 0.2$ & $3.2 \pm 0.2$ \\
\hline
\end{tabular}

Data are expressed as the mean $\pm \operatorname{SD}(n=3)$.

a Protein recovery is the ratio between proteins eluted after chromatography and the total protein loaded, as measured by Lowry's method.

${ }^{b} \mathrm{~B}-\mathrm{PE}$ recovery is the ratio between total B-PE eluted from chromatographic columns and total B-PE loaded, as determined with equation system by measures of absorbances at 545, 620 and $650 \mathrm{~nm}$ media. Moreover, SOURCE 15Q can be applied on FPLC, which can be readily scaled to industrial production of kilograms of purified protein in columns with volumes of many liters. The conventional chromatography methods employed in the purification of B-PE from $P$. cruentum involve gel filtration (Sephadex), DEAE chromatography, expanded bed adsorption (EBA) chromatography, often in combination $[11,12,18,30]$. By our protocol, using only a one-step SOURCE $15 \mathrm{Q}$ chromatography method, purity ratio of the B-PE of $P$. cruentum was enhanced by a factor of 2.6. Compared with the studies on the purification of B-PE implementing more complex procedures, this protocol reduced the processing time, which is advantageous to the preservation of the native conformation of $\mathrm{B}$ PE.

\section{Conclusion}

In this study, involving osmotic shock, ultrafiltration, and onestep SOURCE 15Q chromatography method for extraction and purification of B-PE, analytical grade B-PE was obtained with a purity ratio $\left(A_{545} / A_{280}\right)$ of 5.1 and a yield of $68.5 \%$. The efficiency of this procedure was confirmed by the absorption spectrum, fluorescence spectrum, native PAGE, and SDS-PAGE. Moreover, the procedure is a feasible alternative for industrial scale-up since it can adapt to continuous process and is simple to carry out in large scale. Thus, our protocol represents attractive alternatives to consider for the purification stage to obtain analytical grade B-PE at commercial level.

\section{Acknowledgements}

We are thankful to Professor Liqin Sun for providing Porphyridium cruentum. This work was supported by Ocean Public Welfare Scientific Research Project (Grant No. 20120527), State Oceanic Administration, People's Republic of China.

\section{References}

[1] M. Munier, M. Morançais, J. Dumay, P. Jaouen, J. Fleurence, One-step purification of R-phycoerythrin from the red edible seaweed Grateloupia turuturu, J. Chromatogr. B 992 (2015) 23.

[2] K. Sanjiv, A. Shrivastav, S. Mishra, Preparation of highly purified C-phycoerythrin from marine cyanobacterium Pseudanabaena sp, Protein Expr. Purif. 80 (2011) 234.

[3] R. MacColl, Cyanobacterial phycobilisomes, J. Struct. Biol. 124 (1998) 311.

[4] Y.M. Zhang, F. Chen, A simple method for efficient separation and purification of C-phycocyanin and allophycocyanin from Spirulina platensis, Biotechnol. Technol. 13 (1999) 601.

[5] K.E. Apt, J.L. Collier, A.R. Grossman, Evolution of the phycobiliproteins, J. Mol. Biol. 248 (1995) 79.

[6] J. Dumay, M. Morancais, M. Munier, C. Le Guillard, J. Fleurence, Advances in Botanical Research, Sea Plants, Elsevier, 2014, p. pp.580.

[7] A.N. Glazer, Light harvesting by phycobilisomes, Annu. Rev. Biophys. Biophys. Chem. 14 (1985) 47.

[8] A. Parmar, N.K. Singh, A. Kaushal, S. Sonawala, D. Madamwar, Purification, characterization and comparison of phycoerythrins from three different marine cyanobacterial cultures, Bioresour. Technol. 102 (2011) 1795.

[9] F. Ruiz-Ruiz, J. Benavides, M. Rito-Palomares, Scaling-up of a B-phycoerythrin production and purification bioprocess involving aqueous two-phase systems: practical experiences, Process Biochem. 48 (2013) 738.

[10] A. Marcati, A.V. Ursu, C. Laroche, N. Soanen, L. Marchal, S. Jubeau, G. Djelveh, P. Michaud, Extraction and fractionation of polysaccharides and B-phycoerythrin from the microalga Porphyridium cruentum by membrane technology, Algal Res. 5 (2014) 258.

[11] R. Bermejo, J.M. Alvarez-Pez, F.G. Acién, J. Fernandez, E. Molina, Recovery of pure B-phycoerythrin from the microalga Porphyridium cruentum, J. Biotechnol. 93 (2002) 73

[12] R. Bermejo, E.M. Talavera, J.M. Alvarez-Pez, Chromatographic purification and characterization of B-phycoerythrin from Porphyridium cruentum-semipreparative HPLC separation and characterization of its subunits, J. Chromatogr. A 917 (2001) 135.

[13] S.N. Tripathi, S. Kapoor, A. Shrivastave, Extraction and purification of an unusual phycoerythrin in a terrestrial desiccation tolerant cyanobacterium Lyngbya arboricola, J. Appl. Phycol. 19 (2007) 441. 
[14] L. Sun, S. Wang, L. Chen, X. Gong, Promising fluorescent probes from phycobiliproteins, IEEE J. Sel. Top. Quantum Electron. 9 (2003) 177.

[15] A.N. Glazer, Phycobiliproteins-a family of valuable, widely used fluorophores, J. Appl. Phycol. 6 (1994) 105.

[16] S. Arad, A. Yaron, Natural pigments from red microalgae for use in foods and cosmetics, Trends Food Sci. Technol. 3 (1992) 92.

[17] M. Ayyagari, R. Pande, S. Kamtekar, H. Gao, K. Marx, J. Kumar, S. Tri-pathy, J. Akkara, D. Kaplan, Molecular assembly of proteins and conjugated polymers: toward development of biosensors, Biotechnol. Bioeng. 45 (1995) 116

[18] J. Benavides, M. Rito Palomares, Bioprocess intensification: a potential aqueous two-phase process for the primary recovery of B-phycoerythrin from Porphyridium cruentum, J. Chromatogr. B 807 (2004) 33.

[19] J. Qiu, J. Madoz-Gurpide, D.E. Misek, R. Kuick, D.E. Brenner, G. Michailids, B.B. Haab, G.S. Omenn, S.J. Hanash, Development of natural protein microarrays for diagnosing cancer based on an antibody response to tumor antigens, Proteome Res. 3 (2004) 261.

[20] S. Sekar, M.P. Chandramohan, Phycobiliproteins as a commodity: trends in applied research, patents and commercialization, J. Appl. Phycol. 20 (2008) 113.

[21] J.J. Kim, Y.M. Jeon, J.H. Noh, L. Mi-Young, Isolation and characterization of a new phycoerythrin from the cyanobacterium Synechococcus sp. ECS-18, J. Appl. Phycol. 23 (2011) 137.

[22] J. Benavides, M.R. Palomares, Simplified two-stage method to B-phycoerythrin recovery from Porphyridium cruentum, J. Chromatogr. B 844 (2006) 39.

[23] S. Arad, A. Yaron, Natural pigments from red microalgae for use in foods and cosmetics, Trends Food Sci. Technol. 3 (1992) 92.

[24] C.E. Cai, C.X. Li, Y.Y. Teng, Z.L. Lin, B.Y. Gu, P.M. He, Comparing of crude extraction methods of phycoerythrin from Porphyra yezoensis, J. Shanghai Ocean Univ. 21 (2011) 368.

[25] H.L. Ma, H.F. Xiao, L. Luo, Technology for purifying phycoerythrin extracted from Porphyra yezoensis, Trans. CSAE 23 (2007) 249.

[26] J.F. Niu, G.C. Wang, B.C. Zhou, X.Z. Lin, C.S. Chen, Purification of R-phycoerythrin from Porphyra haitanensis (Bangiales, Rhodophyta) using expanded-bed absorption, J. Phycol. 43 (2007) 1339.

[27] J.F. Niu, G.C. Wang, C.K. Tseng, Method for large-scale isolationand purification of R-phycoerythrin from red alga Polysiphonia urceolata Grev, Protein Expr.
Purif. 49 (2006) 23.

[28] R. Bermejo, F.G. Acién, M. Ibanez, J. Fernandez, E. Molina, J.M. Alvarez-Pez, Preparative purification of B-phycoerythrin from the microalgae Porphyridium cruentum by expanded-bed adsorption chromatography, J. Chromatogr. B 790 (2003) 317.

[29] R. Bermejo, E. Ruiz, F.G. Acien, Recovery of B-phycoerythrin using expanded bed adsorption chromatography: scale-up of the process, Enzyme Microb. Technol. 40 (2007) 927.

[30] A.A. Tcheruov, K.M. Minkova, D.I. Georgiev, N.B. Houbavenska, Method for Bphycoerythrin purification from Porphyridium cruentum, Biotechnol. Technol. 7 (1993) 853.

[31] S. Kathiresan, R. Sarada, S. Bhattacharya, G.A. Ravishankar, Culture media optimization for growth and phycoerythrin production from Porphyridium purpureum, Biotechnol. Bioeng. 96 (2006) 456.

[32] O.H. Lowry, N.J. Rosenbrough, A.L. Farr, R.J. Randall, Protein measurement with the folin phenol reagent, J. Biol. Chem. 193 (1951) 265.

[33] A. Parmar, N.K. Singh, D. Madamwar, Allophycocyanin from a local isolate Geitlerinema sp. A28DM (Cyanobacteria): a simple and efficient purification process, J. Phycol. 46 (2010) 285.

[34] H. Schägger, V.G. Jagow, Tricine-sodium dodecyl sulfate-polyacrylamide gel electrophoresis for the separation of proteins in the range from 1 to $100 \mathrm{kDa}$ Anal. Biochem. 166 (1987) 368.

[35] R. Chaiklahan, N. Chirasuwan, V. Loha, S. Tia, B. Bunnag, Separation and purification of phycocyanin from Spirulina sp. using a membrane process, Bioresour. Technol. 102 (2011) 7159.

[36] G.A. Básaca-Loya, M.A. Valdez, E.A. Enríquez-Guevara, L.E. Gutiérrez-Millán, M.G. Burboa, Extraction and purification of B-phycoerythrin from the red microalga Rhodosorus marinus, Cienc. Mar. 35 (2009) 268.

[37] J. Benavides, M. Rito-Palomares, Simplified two-stage method to B-phycoerythrin recovery from Porphyridium cruentum, J. Chromatogr. B 844 (2006) 39.

[38] T. Hernandez-Mireles, M. Rito-Palomares, Improved recovery of B-phycoerythrin produced by the red microalga Porphyridium cruentum, J. Chem. Technol. Biotechnol. 81 (2006) 989.

[39] T. Redlinger, E. Gant, Phycobilisome structure of Porphyridium cruentum, Plant Physiol. 68 (1981) 1375. 